\title{
The Second Canadian Symposium on Hepatitis C Virus: A call to action
}

\author{
Jason Grebely $\mathrm{PhD}^{1}$, Marc Bilodeau MD², Jordan J Feld MD MPH ${ }^{3}$, Julie Bruneau MD MSc ${ }^{4}$, Benedikt Fischer PhD ${ }^{5}$, \\ Jennifer F Raven $\mathrm{PhD}^{6}$, Eve Roberts MD FRCPC ${ }^{7}$, Norma Choucha ${ }^{2}$, Rob P Myers MD MSc FRCPC ${ }^{8}$, \\ Selena M Sagan $\mathrm{PhD}^{9}$, Joyce A Wilson $\mathrm{PhD}^{10}$, Frank Bialystok $\mathrm{PhD}^{7}$, D Lorne Tyrrell MD PhD FRCP ${ }^{11}$, \\ Michael Houghton $\mathrm{PhD}^{11}$, Mel Krajden MD FRCPC ${ }^{12,13}$; \\ on behalf of the National CIHR Research Training Program in Hepatitis C
}

\begin{abstract}
J Grebely, M Bilodeau, JJ Feld, et al; on behalf of the National CIHR Research Training Program in Hepatitis C. The Second Canadian Symposium on Hepatitis C Virus: A call to action. Can J Gastroenterol 2013;27(11):627-632.
\end{abstract}

In Canada, hepatitis $\mathrm{C}$ virus (HCV) infection results in considerable morbidity, mortality and health-related costs. Within the next three to 10 years, it is expected that tolerable, short-duration (12 to 24 weeks) therapies capable of curing $>90 \%$ of those who undergo treatment will be approved. Given that most of those already infected are aging and at risk for progressive liver disease, building research-based interdisciplinary prevention, care and treatment capacity is an urgent priority. In an effort to increase the dissemination of knowledge in Canada in this rapidly advancing field, the National CIHR Research Training Program in Hepatitis C (NCRTP-HepC) established an annual interdisciplinary Canadian Symposium on Hepatitis C Virus. The first symposium was held in Montreal, Quebec, in 2012, and the second symposium was held in Victoria, British Columbia, in 2013. The current article presents highlights from the 2013 meeting. It summarizes recent advances in HCV research in Canada and internationally, and presents the consensus of the meeting participants that Canada would benefit from having its own national HCV strategy to identify critical gaps in policies and programs to more effectively address the challenges of expanding HCV screening and treatment.

Key Words: Biomedical; Canada; Epidemiology; HCV; Public health; Social science

\section{Le deuxième symposium canadien sur le virus de l'hépatite $\mathrm{C}$ : un appel à l'action}

Au Canada, l'infection par le virus de l'hépatite C (VHC) est responsable d'une morbidité, d'une mortalité et de coûts de santé considérables. D'ici trois à dix ans, on prévoit approuver de thérapies tolérables et de courte durée (de 12 à 24 semaines), en mesure de guérir plus de $90 \%$ des personnes traitées. Puisque la plupart des personnes déjà infectées vieillissent et sont vulnérables à une maladie hépatique progressive, il est urgent de créer une capacité interdisciplinaire de prévention, de soins et de traitement fondée sur la recherche. Dans un effort pour accroître le transfert du savoir au Canada dans ce domaine en rapide progression, la Subvention nationale de formation des IRSC sur l'hépatite C (NCRTP-HepC) a créé un symposium interdisciplinaire canadien annuel sur le virus de l'hépatite C. Le premier symposium a eu lieu à Montréal, au Québec en 2012, et le deuxième, à Victoria, en Colombie-Britannique, en 2013. Le présent article expose les faits saillants du symposium de 2013. Il contient un résumé des récents progrès de la recherche sur le VHC au Canada et sur la scène internationale, et le consensus des participants à ce symposium selon lequel le Canada profiterait de sa propre stratégie nationale sur le VHC pour déterminer les lacunes importantes des politiques et des programmes afin de résoudre avec plus d'efficacité le dépistage et le traitement du VHC.

\footnotetext{
In Canada, hepatitis $\mathrm{C}$ virus (HCV) infection results in considerable 1 morbidity, mortality and health-related costs (1-4). Approximately $15 \%$ to $25 \%$ of those infected will develop cirrhosis, liver cancer or require a liver transplant (5). A study from Ontario (6) found that $\mathrm{HCV}$ causes more years of life lost than any other infectious disease in the province. Current therapies can cure approximately $65 \%$ to $75 \%$ of patients (7-12); however, many individuals remain undiagnosed (1). Among those who are diagnosed, treatment assessment and uptake is low overall (estimated to be $<15 \%$ ), especially in people who inject drugs (PWID) (approximately 1\%) (13). This group represents the core of the HCV epidemic in Canada, accounting for the majority of new $(80 \%)$ and existing $(60 \%)$ infections $(1,14)$. In Canada, a Strategic Framework for Action for HCV was released in 2009 by the Public Health Agency of Canada (PHAC) (15), and the consensus guidelines for the management of HCV were updated and published by the Canadian Association for the Study of the Liver in 2012 (16). However, Canada still lacks a national 'action plan' or 'strategy' to address the burden of HCV infection.
}

The Canadian Institutes of Health Research (CIHR) and the PHAC have identified HCV-related liver disease as a major health problem. Within the next three to 10 years, it is expected that tolerable, short-duration (12 to 24 weeks) therapies capable of curing $>90 \%$ of those who undergo treatment will be approved (17-21). Given that most of those already infected are aging and at risk for progressive liver disease (5), building research-based interdisciplinary prevention, care and treatment capacity is an urgent priority. The new therapeutic regimens have the potential to eliminate HCV disease in Canada and worldwide if proven strategies and policies to improve prevention, diagnosis and clinical care are adopted. A national HCV strategy in Canada would fill a critical gap in existing policies and programs to address individuals infected with HCV.

Once well-tolerated treatments with high cure rates are widely available and combined with prevention interventions, marked reductions in morbidity and mortality are expected. Specifically, incident HCV, especially among PWID - who represent the core transmitters of infection - could be dramatically reduced or eliminated. However, to

${ }^{1}$ The Kirby Institute, The University of New South Wales, Sydney, New South Wales, Australia; ${ }^{2}$ Liver Unit, Department of Medicine, Université de Montréal, Montréal, Québec; ${ }^{3}$ Toronto Centre for Liver Disease, University of Toronto, Toronto, Ontario; ${ }^{4} \mathrm{CRCHUM,} \mathrm{Université} \mathrm{de} \mathrm{Montréal,}$ Montréal, Québec; ${ }^{5}$ Simon Fraser University, Vancouver, British Columbia; ${ }^{6}$ Canadian Institutes of Health Research - Institute of Infection and Immunity, Laurier, Québec; ${ }^{7}$ University of Toronto, Toronto, Ontario; ${ }^{8}$ Liver Unit, Division of Gastroenterology and Hepatology, University of Calgary, Calgary, Alberta; ${ }^{9}$ Department of Microbiology 89 Immunology, McGill University, Montreal, Quebec; ${ }^{10}$ Department of Microbiology and Immunology, University of Saskatchewan, Saskatoon, Saskatchewan; ${ }^{11} \mathrm{Li}$ Ka Shing Institute of Virology, University of Alberta, Edmonton, Alberta;

${ }^{12}$ British Columbia Centre for Disease Control; ${ }^{13}$ University of British Columbia, Vancouver, British Columbia

Correspondence and reprints: Dr Jason Grebely, The Kirby Institute, The University of New South Wales, Sydney, New South Wales 2054, Australia. Telephone 61-29-385-0957, fax 61-29-385-0876, e-mail jgrebely@kirby.unsw.edu.au

Received for publication July 15, 2013. Accepted September 15, 2013 
achieve the benefits, case identification and treatment uptake, especially among difficult-to-reach populations, will have to increase dramatically. In an effort to increase the dissemination of knowledge in Canada in this rapidly advancing field, the National CIHR Research Training Program in Hepatitis C (NCRTP-HepC) established an annual interdisciplinary Canadian Symposium on Hepatitis C Virus. The first symposium was held in Montreal, Quebec, in 2012, and the second symposium was held in Victoria, British Columbia, in 2013. Symposium participants included selected researchers and graduate research (including $\mathrm{MSc}, \mathrm{PhD}$ and postdoctoral) trainees, health care practitioners, public health professionals, health policy makers and members of the affected community. The interdisciplinary program included sessions on biomedical, clinical, health services and social, cultural, environmental and population health research. The current article presents highlights from the 2013 meeting. It summarizes recent advances in HCV research in Canada and internationally, and presents the consensus of the meeting participants that Canada would benefit from having its own national HCV strategy to identify critical gaps in policies and programs to more effectively address the challenges in expanding HCV screening and treatment. The concern is that without a well-articulated action plan, the public health and economic benefits from the potential curability of $\mathrm{HCV}$ will fail to materialize.

\section{NCRTP-HEPC}

The NCRTP-HepC is a CIHR-funded strategic training initiative established in 2001 that has received a wide range of support from both public (eg, CIHR and PHAC) and nongovernmental organizations (eg, the Canadian Liver Foundation), industry, as well as private and community partners to build interdisciplinary research capacity, promote leadership and enhance HCV awareness (www.ncrtp-hepc. $\mathrm{ca} /$ ). The NCRTP-HepC was designed to foster cross-disciplinary learning and collaboration among clinical, basic biomedical, social/ cultural/environmental/population health and health systems/services researchers, from disciplines including medicine, nursing and social sciences. The overall goal is to increase interdisciplinary Canadian research and training capacity to reduce HCV disease burden.

The NCRTP-HepC provides stipend support to graduate students, postdoctoral trainees and MD trainees who have demonstrated excellence early in their careers. Trainees are under the guidance of one of 30 mentors located at 10 Canadian universities. These mentors have expertise in multiple disciplines and have had a proven track record in the field of HCV-related research. The program provides for a unique interdisciplinary training environment, which includes web-based courses, journal clubs, and opportunities to present at national and international meetings. Trainees also have the option of participating in short-term training sabbaticals to gain research experience with other mentors. Since its creation in 2001, the NCRTP-HepC program has successfully enhanced Canadian HCV research capacity, knowledge translation and interdisciplinary collaboration and, more recently, in part through the coordination of the Canadian Symposium on Hepatitis C Virus, has made major strides in knowledge dissemination.

Building from the experience of the 2012 meeting in Montreal, the specific aims of the Second Canadian Symposium on Hepatitis C Virus were:

1. To facilitate transdisciplinary knowledge exchange and collaborations among Canadian trainees, established researchers, health care practitioners, health policy makers and communitybased groups working in the field of HCV research;

2. To discuss strategies that could enable the eradication of HCV in Canada; and

3. To implement, plan and deliver knowledge exchange and dissemination of symposium findings and translate these to support practice change, community awareness and policy development.

\section{THE SECOND CANADIAN SYMPOSIUM ON HEPATITIS C VIRUS}

To foster cross-disciplinary research translation, the program for the Canadian Symposium on Hepatitis C Virus is based on a 'cell-to-society' approach, consisting of themed sessions focusing on biomedical sciences, clinical sciences, social and behavioural sciences, and epidemiology/population health. Each session consisted of plenary sessions by international and national experts, and oral abstract presentations.

\section{Biomedical Sciences}

Although relatively effective, current therapy is very challenging to deliver due to numerous side effects, long treatment durations (24 to 48 weeks), the need for injections and high cost. It is expected that highly effective, tolerable and simplified therapy will be available over the next several years (17-21). However, it is unlikely that people will be treated in sufficient numbers to control the HCV epidemic, given the current low treatment uptake among PWID and other marginalized populations who are at greatest risk for incident HCV infection. Furthermore, the high costs of direct-acting antiviral (DAA)-based therapies may also preclude universal delivery, particularly in developing countries. As such, prevention through vaccination remains an alternative and potentially effective strategy to prevent incident HCV infections, and development of a HCV vaccine remains an urgent medical priority (22). However, the multitude of HCV genotypes, which are geographically dispersed, and the high rate of sequence mutations that occur during $\mathrm{HCV}$ replication makes it a major challenge to induce cross-protective vaccine immunity. For example, even spontaneous HCV clearance after acute infection does not induce sterilizing immunity (eg, absolute protection against HCV reinfection). This highlights the difficulties in designing a vaccine that is capable of inducing a better immune response than natural infection.

As reviewed elsewhere $(22,23)$, existing data obtained in chimpanzees and PWID suggest that at least some degree of protective immunity against persistent $\mathrm{HCV}$ infection is possible. However, the design of a prophylactic vaccine against HCV has been hampered by the limited knowledge of functional signatures of a protective immune response on re-exposure in real-life settings $(22,23)$. A study by Abdel-Hakeem et al (24), presented at this meeting, described a detailed longitudinal analysis of the immune response among PWID $(n=10)$ during multiple episodes of HCV infection. These individuals spontaneously cleared previous HCV infection and were reinfected. Some cleared again while others progressed to chronic infection. Comparing the immune responses over time, differences were found in the magnitude, breadth and quality (phenotype and functionality) of responses to HCV peptides. Data from this study suggest that protection from persistence on reinfection with $\mathrm{HCV}$ was associated with a pronounced expansion and increase in the breadth of the HCV-specific memory response, providing important insights into some of the required components of a successful immune response in humans.

Additional findings were presented in relation to understanding the requirements for a prophylactic $\mathrm{HCV}$ vaccine. In a study presented by Professor Takaji Wakita from the National Institute of Infectious Diseases in Japan, purified HCV particles produced in cell culture were inactivated and injected with adjuvant into mice $(25,26)$. Antisera from the immunized mice inhibited HCV infection in cell culture. It was confirmed that purified antibodies from immunized mice were able to prevent infection in human liver-chimeric uPA-SCID mice, at least at the minimum infectious dose. These results suggest that inactivated HCV particles produced in cell culture can induce broad crossneutralizing antibodies against HCV infection, which, in turn, could form the basis for a prophylactic vaccine.

In an additional study presented by Professor Michael Houghton, sera from healthy human volunteers vaccinated with a recombinant HCV envelope glycoproteins (gpE1/gpE2) were screened for neutralization activity against the major HCV genotypes in cell culture $(27,28)$. At least one vaccinee developed broad cross-neutralization against all known major HCV genotypes. This is a significant advance 
because it suggests that cross-neutralizing activity is possible with a vaccine derived from a single HCV strain. Further research will focus on analyzing the identity of cross-neutralizing epitopes. These results suggest that one or more cross-neutralizing epitopes are conserved between the six or seven major HCV genotypes despite the considerable genetic heterogeneity.

These studies represent significant advances in our understanding of how the generation of cross-neutralizing antibodies could be used to develop a prophylactic HCV vaccine. The first prophylactic HCV vaccine trial in at-risk PWID was initiated in 2012 (22) and will provide important information on how effective the vaccine is at preventing chronic HCV infection. Further vaccine research is needed, given the potential prevention benefits of vaccines at reducing transmission in core transmitter populations, particularly in PWID.

\section{Clinical Sciences}

This session focused on the development and availability of novel, potent and well-tolerated DAAs that will have the potential to significantly improve the uptake and curability of $\mathrm{HCV}$ infection at the population level. In a plenary session at the meeting, Dr Jordan Feld highlighted the fact that new DAA agents will initially improve either efficacy or tolerability, with some sacrifice of one for the other (29). Although current triple therapy with first-generation protease inhibitors offers an improvement in treatment efficacy, this has come at the price of tolerability when compared with pegylated interferon alfa-2a (PEGIFN) and ribavirin alone (Figure 1). In the near term, several key clinical trials are exploring better-tolerated second-generation DAAs with a PEG-IFN backbone (30) or 'quad' therapies with two DAAs and PEGIFN and ribavirin. The trials are also exploring well-tolerated interferonfree DAA combinations that appear to be promising but have only been tested in small numbers of highly selected patients $(17-21,31)$. Ultimately, Dr Feld predicted that oral, well-tolerated, highly efficacious therapies will be available with either a polymerase and/or potent protease inhibitor backbone and will be capable of curing almost all treated patients. Dr Feld coined the term 'perfectovir' as the holy grail of HCV treatment, a drug with no or few side effects, once-daily dosing and near $100 \%$ treatment response. This is clearly a therapeutic goal that researchers and industry are striving for.

The prospect of well-tolerated oral therapies increases the feasibility of using treatment as tool for HCV disease elimination. Professor Gregory Dore from the University of New South Wales in Australia highlighted that HCV-related morbidity and mortality, including extrahepatic consequences, continues to increase globally, emphasizing the need to eliminate this pathogen (32). He pointed out that elimination of HCV infection will likely require a broad expansion of treatment, which ideally would be government funded, primary carebased and focused in groups at high risk for spreading the infection (PWID, incarcerated individuals, HIV-infected men who have sex with men and pregnant mothers). Modelling data suggest that HCV treatment in highly prevalent populations can reduce transmission and, ultimately, prevalence, using the paradigm of treatment as prevention. However, Dr Dore noted that for these interventions to have a beneficial effect, major challenges must be overcome, including increased advocacy to drive expansion of public funding and price reform in the pharmaceutical industry. He concluded his remarks with a sense of tempered optimism, acknowledging that true elimination may be unlikely. However, given the prospect of well-tolerated, highly effective, short-course DAA-based therapies, major strides could be made to substantially reduce the burden of HCV-related disease in Canada and globally if affected communities, health care providers and governments made this a priority.

\section{Social and Behavioural Sciences}

In Canada, the large majority of individuals infected with HCV represent people who may have injected drugs in the past, or who are currently involved in ongoing drug use. Many are characterized by highly marginalized socioeconomic conditions (eg, homelessness, poverty, etc) $(1,14)$. These basic parameters regarding the principal risk groups

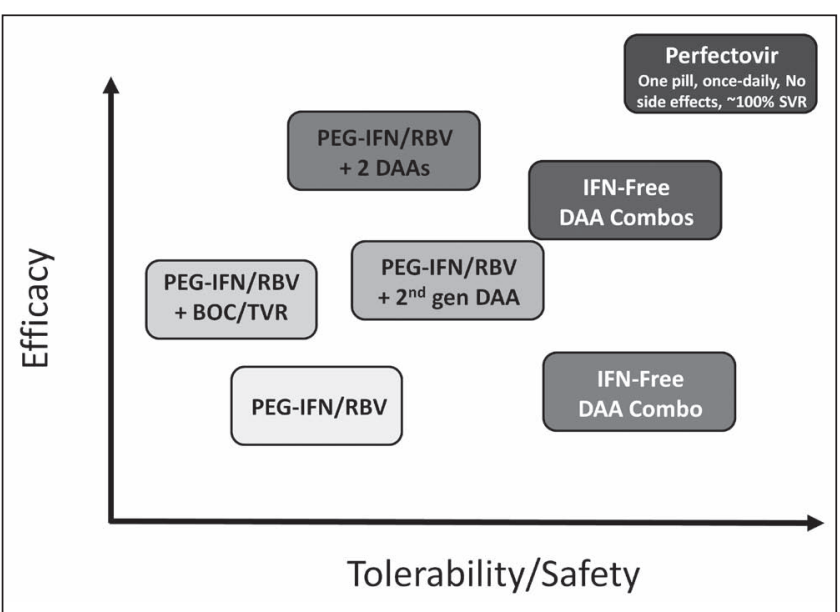

Figure 1) The hepatitis $C$ virus drug development process over the next five to 10 years may not be linear. BOC Boceprevir; Combos Combinations; DAA Direct-acting antiviral agent; gen Generation; IFN Interferon; PEGIFN Pegylated IFN; RBV Ribavirin; SVR Sustained virological response; TVR Telaprevir

for HCV infection impact distinct and important components at both the social and behavioural levels when it comes to interventions for $\mathrm{HCV}$ infection. Despite rapidly improving and expanding HCV treatment options, it has been a major challenge in Canada and elsewhere to design and deliver HCV treatment in ways that optimally reflect and respond to the distinct behavioural needs and social characteristics of the principle risk/target populations (33). In a qualitative research framework, Professor Tim Rhodes from the London School of Hygiene and Tropical Medicine (London, United Kingdom) explored how the negotiation of access to HCV treatment by individuals who have injected drugs in many ways entails a comprehensive struggle of 'recovery toward normality' in societal processes defined by inclusion and exclusion (34-36). In practice, to those affected, it can mean the necessity to exercise self-control, and to conform with rules and regulations required for treatment, which were rejected while existing as a drug user at the margins of society - a process Professor Rhodes describes as the 'making of patient citizenship', in which access to treatment is experienced not primarily as an entitlement, but through gratitude. While treatment is sought and desired, it can only be obtained at the 'price' of playing by rules set by others (eg, the medical system). A further key challenge was addressed in a study by Sockalingham et al (37) from the University of Toronto (Toronto, Ontario), concerning the efforts on how to keep marginalized and comorbid (eg, with high levels of co-occurring substance use and mental health problems) patients engaged in HCV treatment. They found that a regular (weekly) psychosocial support group for a sample of 163 patients in a community-based HCV treatment program was attended frequently, and was associated with good group cohesion and an improvement in patients' depression and anxiety measures. All of these studies provide important sociobehavioural data related to how to better support marginalized populations to access and engage in HCV treatment; however, further research is needed.

\section{Epidemiology and Public Health}

Efforts to expand access to HCV treatment will require improved strategies for screening, testing and assessment of infection. Dr Bryce Smith, from the United States Centers for Disease Control and Prevention (CDC; Georgia, USA), made a case for population-based HCV screening in the United States, specifically targeting 'baby boomers' (individuals born between 1945 and 1965) (38,39). While population-based screening is commonly used for cancer prevention, it is rarely applied for infectious diseases. However, studies of prevention efforts conducted in many countries, including Romania, Pakistan, Spain, Egypt and Japan, showed that population-based screening in 
high-prevalence settings could be a cost-effective case identification approach. For example, in $2007,70 \%$ of deaths and $76 \%$ of all cases in $\mathrm{HCV}$-infected populations in the United States were among people 45 to 64 years of age (40). Individuals born between 1945 and 1965 have a fivefold increased risk of being HCV positive, compared with those born between 1941 and 1945 (39).

In contrast, a study conducted by Dr Maxim Trubnikov from PHAC found that the birth cohort with the highest reported rate of $\mathrm{HCV}$ comprised Canadians born between 1945 and 1975 (41), a wider age range than in the United States (39). While Canadian baby boomers remained the age cohort (1945 to 1965) with the highest reported rates of $\mathrm{HCV}$ infection, the cohort effect extended to younger individuals born up to 1975 and demonstrated slight differences in prevalence between the sexes (41). In Canadian males, the relative excess in HCV infection was found in those born up to 1970 whereas in females, the effect was present in those born up to 1975 (41). Similarly, for the undiagnosed HCV infections in Canada, Dr Tom Wong from PHAC highlighted a birth cohort effect, with the highest estimated burden occurring in those born between 1950 and 1979 (42).

Dr Bryce Smith and Professor Gregory Dore engaged in a spirited debate, titled "Testing and Screening for Hepatitis C Virus Infection: Should We Screen Everyone Born Between 1945-1965?" On the 'Pro' side, Dr Smith focused on issues related to the increasing morbidity and mortality among HCV-infected people in the United States and highlighted the limitations of risk-based and liver enzyme-based strategies for HCV screening. He presented evidence that birth cohort screening in the United States was a cost-effective strategy, thus forming the basis of the CDC recommendation that in the United States, "CDC strongly recommends adults born during 1945-1965 should receive one-time testing for $\mathrm{HCV}$ without prior ascertainment of HCV risk factors", but suggested that risk-based screening to continue (39). On the 'Con' side, Dr Dore argued that the United States birthcohort screening approach might have some limitations, given that surveillance data often exclude marginalized populations (eg, PWID), and these groups are not included in sentinel and population-based surveys. Dr Dore suggested that moving away from a risk-based screening strategy may indirectly further promote HCV-related stigma and discrimination. In addition, he highlighted that the cost-effectiveness analyses of birth-cohort screening may be overestimated, given assumptions that potentially overestimate liver disease progression rates and screening/assessment/uptake rates. Furthermore, he questioned the utility of birth-cohort screening in settings with very high proportions of diagnosed individuals such as Australia and, perhaps, Canada. If the estimate that most Canadians with HCV had already been diagnosed was correct, then the incremental benefits of cohort screening may be less important at the population level than by engaging those already diagnosed, into treatment. The major thrust of the discussion focused on the lack of reliable estimates of the HCV disease burden in Canada. It was clear from this discussion that deriving better population-level HCV incidence and prevalence estimates is critically necessary, not only to inform screening policies but to support decisions on how best to implement care and treatment programs.

In addition to HCV testing, assessment of liver disease is also important. Canadian guidelines recommend that all HCV patients undergo an assessment for the stage of liver fibrosis. A Canadian nationwide survey of physician practices for liver fibrosis assessment conducted by Sebastiani et al (43) (McGill University, Montreal, Quebec) demonstrated that noninvasive procedures were preferred overall (43). However, the survey also showed that accessibility and the lack of guidelines in clinical practice were two factors hindering the use of noninvasive procedures such as Fibroscan (Echosens, France). This explains why $40 \%$ of respondents reported using liver biopsies - which are more costly and invasive (but possibly more accurate) - as their primary liver fibrosis assessment method.

With more emphasis on screening of baby boomers, and with the projected availability of new pharmacotherapies that treat $\mathrm{HCV}$ efficiently and effectively, Professor Murray Krahn, from the University of Toronto, discussed modelling as a useful research method to inform policy development (44). Data that support the cost effectiveness of screening immigrants from specific countries for $\mathrm{HCV}$ were presented, and highlighted the importance of response-guided therapies to increase therapeutic cost effectiveness.

\section{OUTCOMES OF THE SECOND CANADIAN SYMPOSIUM ON HEPATITIS C VIRUS}

This symposium highlighted the fact that within the past 25 years, scientific progress has transformed the unknown non-A non-B hepatitis agent into a curable viral illness. Given the looming human and societal costs of untreated HCV infection but, also, the potential for therapies with near-universal cure rates, a strategic and proactive public health response is urgently required to reduce HCV-related morbidity and mortality in a cost-effective manner.

This meeting underscored that the quest for an HCV vaccine has made great strides over the past several decades and the potential for a prophylactic vaccine that prevents chronic $\mathrm{HCV}$ infection may be possible within the next decade. In the short term, new antivirals are expected to achieve very high cure rates $(>90 \%)$ with short treatment durations. However, without a substantial increase in the proportion of the infected population that receives treatment, these new therapies will not achieve the population impact required to substantially reduce the burden of HCV infection in Canada.

In Canada, this will likely require a multipronged approach. First, a major group affected by HCV includes current or former PWID. Often PWID have multiple comorbid conditions, including addictions, mental health issues and social vulnerabilities, that impact their decisions around treatment and also place them at risk for other complications, such as HIV coinfection, which accelerates HCV disease progression (33). These populations also face stigma and discrimination, which in turn adversely impacts diagnosis and access to care. Because this group represents the majority of the core transmitters of incident HCV infections, from a public health perspective, preventing $\mathrm{HCV}$ transmission in this group remains an important priority. A proactive response will require programs that encourage testing, engagement in comprehensive care (including harm reduction as well as addiction and mental health support), as well as studies to assess how best to apply 'treatment as prevention' to prevent ongoing HCV transmission while retaining individuals in care to prevent reinfection (45).

The second group affected by HCV includes Canadian 'baby boomers' (those born between 1945 and 1965, and perhaps 1975), most of whom were infected decades ago. Because most baby boomers no longer engage in high-risk activities, they are unlikely to transmit infection but remain at risk for developing cirrhosis, liver cancer and extrahepatic HCV-related diseases (eg, lymphoma). Given that most $\mathrm{HCV}$ infections are asymptomatic until patients present with endstage liver disease or liver cancer, many baby boomers remain unaware that they are infected. For baby boomers, a proactive HCV strategy should perhaps include both risk-based and one-time testing followed by engagement in care and treatment, which has been proven to reduce HCV-related morbidity and mortality (39). Finally, given the fact that immigrants from countries with high prevalence of HCV are estimated to account for $20 \%$ of Canadians infected with HCV, this represents another important risk group that could benefit from HCV screening and engagement in care and treatment.

This symposium highlighted that if proven public health strategies are implemented, HCV disease could be eliminated within the next generation. The solution would need to be multipronged and focus on curing and preventing transmission in core transmitters (PWID) as well as curing infections in baby boomers. However, without active identification of those infected, engagement in care and treatment, provision of comprehensive follow-up and support, the individual and public health benefits of these curative therapies will not materialize. In Canada, there is currently no national 'action plan' or 'strategy' to 
reduce the transmission of, and morbidity and mortality caused by HCV. To date, the implementation of a national HCV strategy has been challenging because the provision of health services in Canada are under provincial jurisdiction. However, national HCV 'strategy' or 'action plans' have been developed and implemented in countries such as Australia (46), Scotland (47) and the United States (48). Given that $\mathrm{HCV}$ is preventable and will be soon close to universally curable, the impact of adopting a national HCV 'strategy' or 'action plan' could help mobilize the resources to profoundly impact the HCV-related health outcomes at the individual and population levels.

ACKNOWLEDGEMENTS: National CIHR Research Training Program in Hepatitis C (NCRTP-HepC) Mentors - Marc Bilodeau (Program Director, Université de Montréal), Norma Choucha (Program Administrator, Université de Montréal), Louise Balfour (University of Ottawa), Julie Bruneau (Université de Montréal), Gail Butt (University of British Columbia), Brian Conway (Vancouver Infectious Diseases Centre), Curtis Cooper (University of Ottawa), Aled Edwards (University of Toronto), Jordan Feld (University of Toronto), Benedikt Fischer (Simon Fraser University), Matthias Götte (McGill University), Jason Grebely (University of New South Wales), Michael Houghton (University of Alberta), Marina Klein (McGill University), Norman Kneteman (University of Alberta), Murray Krahn (University of Toronto), Mel Krajden (University of British Columbia), Gary Levy (University of Toronto), Qiang Liu (University of Saskatchewan), Ian McGilvray (University of Toronto), Thomas Michalak (Memorial University), Gerry Mugford (Memorial University), Rob Myers (University of Calgary), Mario Ostrowski (University of Toronto), Arnim Pause (McGill University), John Pezacki (University of Ottawa), Chris Richardson (Dalhousie University), Eve Roberts (University of Toronto), Rod Russell (Memorial University), Luis Schang (University of Alberta), Naglaa

\section{REFERENCES}

1. Remis R. Modelling the incidence and prevalence of hepatitis $C$ infection and its sequelae in Canada, 2007. Final Report. Ottawa: Health Canada, 2007.

2. Myers RP, Liu M, Shaheen AA. The burden of hepatitis $C$ virus infection is growing: A Canadian population-based study of hospitalizations from 1994 to 2004. Can J Gastroenterol 2008;22:381-7.

3. Yu A, Spinelli JJ, Cook DA, Buxton JA, Krajden M. Mortality among British Columbians testing for hepatitis $\mathrm{C}$ antibody. BMC Public Health 2013;13:291.

4. Krajden M, Kuo M, Zagorski B, Alvarez M, Yu A, Krahn M. Health care costs associated with hepatitis C: A longitudinal cohort study. Can J Gastroenterol 2010;24:717-26.

5. Grebely J, Dore GJ. What is killing people with hepatitis C virus infection? Semin Liver Dis 2011;31:331-9.

6. Kwong JC, Ratnasingham S, Campitelli MA, et al. The impact of infection on population health: Results of the Ontario burden of infectious diseases study. PLoS One 2012;7:e44103.

7. Manns MP, McHutchison JG, Gordon SC, et al. Peginterferon alfa-2b plus ribavirin compared with interferon alfa- $2 \mathrm{~b}$ plus ribavirin for initial treatment of chronic hepatitis C: A randomised trial. Lancet 2001;358:958-65.

8. Fried MW, Shiffman ML, Reddy KR, et al. Peginterferon alfa-2a plus ribavirin for chronic hepatitis $\mathrm{C}$ virus infection. N Engl J Med 2002;347:975-82.

9. Poordad F, McCone J Jr, Bacon BR, et al. Boceprevir for untreated chronic HCV genotype 1 infection. N Engl J Med 2011;364:1195-206.

10. Jacobson IM, McHutchison JG, Dusheiko G, et al. Telaprevir for previously untreated chronic hepatitis $\mathrm{C}$ virus infection. N Engl J Med 2011;364:2405-16.

11. Sherman KE, Flamm SL, Afdhal NH, et al. Response-guided telaprevir combination treatment for hepatitis $\mathrm{C}$ virus infection. N Engl J Med 2011;365:1014-24.

12. Zeuzem S, Andreone P, Pol S, et al. Telaprevir for retreatment of HCV infection. N Engl J Med 2011;364:2417-28.

13. Grebely J, Raffa JD, Lai C, et al. Low uptake of treatment for hepatitis $C$ virus infection in a large community-based study of inner city residents. J Viral Hepat 2009;16:352-8.

14. PHAC. Hepatitis C in Canada: 2005-2010 Surveillance Report. Ottawa: Centre for Communicable Diseases and Infection
Shoukry (Université de Montréal), Nahum Sonenberg (McGill University), Hugo Soudeyns (Université de Montréal), Raymond Tellier (University of Toronto), Mark Tyndall (University of Ottawa), Lorne Tyrrell (University of Alberta), and Joyce Wilson (University of Saskatchewan). Postdoctoral Trainees -Jean-Marie Bamvita (Université de Montréal), Marion Depla (Université de Montréal), Sonya MacParland (University of Toronto), and Selena Sagan (Stanford University). PhD Trainees - Mohamed AbdelHakeem (Université de Montréal), Brett Hoffman (University of Saskatchwan), Anupriya Kulkarni (McGill University), Nasheed Moqueet (McGill University), Neda Nasheri Ardakan (University of Ottawa), Ragunath Singaravelu (University of Ottawa), Patricia Thibault (University of Saskatchewan), Qi Wu (University of Saskatchewan), and Ahmed Fahmy (Université du Québec). MSc Trainees - Jason Wong (Univerity of Alberta), Kayla Holder (Memorial University), and Georgia Skardasi (Memorial University). Lay members - Frank Bialystok, Andrew Cumming.

FUNDING: The NCRTP-HepC is funded by a Training Grant from the Canadian Institutes of Health Research (CIHR; Grant number 63298). In addition, the NCRTP-HepC receives funding from Abbvie, Boehringer Ingelheim, Bristol Myers Squibb Canada Co., the Canadian Liver Foundation, Gilead, Merck, Novartis, Roche and Vertex. The 1st Canadian Symposium on Hepatitis C Virus (Grant number 264748) and 2nd Canadian Symposium on Hepatitis C Virus (Grant number 290924) were supported by the Canadian Institutes of Health Research. JG is supported through a National Health and Medical Research Council Career Development Fellowship. SMS is an Amgen Fellow of the Life Sciences Research Foundation (LSRF) and was an NCRTP-HepC postdoctoral trainee. The views expressed in this publication are those of the author(s) and do not reflect the position of the CIHR or the Public Health Agency of Canada.

Control, Infectious Disease Prevention and Control Branch, Public Health Agency of Canada, 2011.

15. PHAC. A Renewed Public Health Response to Address Hepatitis C: A summary report of the priority setting process and a strategic framework for action. 2009 [June 29, 2013]. <http://publications. gc.ca/collections/collection_2010/aspc-phac/HP40-44-2009-eng. pdf> (Accessed May 10, 2013).

16. Myers RP, Ramji A, Bilodeau M, Wong S, Feld JJ. An update on the management of hepatitis $\mathrm{C}$ : Consensus guidelines from the Canadian Association for the Study of the Liver. Can J Gastroenterol 2012;26:359-75.

17. Jacobson IM, Gordon SC, Kowdley KV, et al. Sofosbuvir for hepatitis $\mathrm{C}$ genotype 2 or 3 in patients without treatment options. N Engl J Med 2013;368:1867-77.

18. Lawitz E, Mangia A, Wyles D, et al. Sofosbuvir for previously untreated chronic hepatitis $\mathrm{C}$ infection. $\mathrm{N}$ Engl J Med 2013;368:1878-87.

19. Chayama K, Takahashi S, Kawakami Y, et al. Dual oral combination therapy with the NS5A inhibitor BMS-790052 and the NS3 protease inhibitor BMS-650032 achieved $90 \%$ sustained virological response (SVR12) in HCV genotype 1b-infected null responders. . Hepatology 2011;54(4 Suppl):1428A.

20. Lok AS, Gardiner DF, Lawitz E, et al. Preliminary study of two antiviral agents for hepatitis C genotype 1 . N Engl J Med 2012;366:216-24.

21. Poordad F, Lawitz E, Kowdley KV, et al. 12-week interferon-free regimen of ABT-450/r+ABT-333+ribavirin achieved SVR12 in more than $90 \%$ of treatment-naïve HCV genotype-1-infected subjects and 47\% of previous non-responders. J Hepatol 2012;56.

22. Cox AL, Thomas DL. Hepatitis C virus vaccines among people who inject drugs. Clin Infect Dis 2013;57(Suppl 2):S46-50.

23. Grebely J, Prins M, Hellard M, et al. Hepatitis C virus clearance, reinfection, and persistence, with insights from studies of injecting drug users: Towards a vaccine. Lancet Infect Dis 2012;12:408-14.

24. Abdel-Hakeem M, Bédard $1 \mathrm{~N}$, Bruneau J, Shoukry N, eds. Analysis of a protective immune response during multiple episodes of HCV infection. 2nd Canadian Symposium on Hepatitis C Virus. Victoria, March 4, 2013. 
25. Akazawa D, Moriyama M, Yokokawa $\mathrm{H}$, et al. Neutralizing antibodies induced by cell culture-derived hepatitis $\mathrm{C}$ virus protect against infection in mice. Gastroenterology 2013;145:447-55.e1-4 (E-pub ahead of print, May 11).

26. Wakita T, ed. Pathogenesis and vaccine development for HCV infection. 2nd Canadian Symposium on Hepatitis C Virus. Victoria, March 4, 2013.

27. Law JL, Chen $\mathrm{C}$, Wong J, et al. A hepatitis $\mathrm{C}$ virus (HCV) vaccine comprising envelope glycoproteins gpE1/gpE2 derived from a single isolate elicits broad cross-genotype neutralizing antibodies in humans. PLoS One 2013;8:e59776.

28. Houghton M, ed. Vaccinating Canadians against hepatitis C. 2nd Canadian Symposium on Hepatitis C Virus. Victoria, March 4, 2013.

29. Feld JJ, ed. The End of interferon: Direct-acting antiviral therapy for HCV. 2nd Canadian Symposium on Hepatitis C Virus. Victoria, March 4, 2013.

30. Fried M, Sherman M, Dore GJ, et al, eds. TMC435 in combination with peginterferon and ribavirin in treatment-naïve $\mathrm{HCV}$ genotype 1 patients: Final analysis of The PILLAR Phase IIb Study. 2nd Canadian Symposium on Hepatitis C Virus. Victoria, March 4, 2013.

31. Hofmann WP, Zeuzem S. A new standard of care for the treatment of chronic HCV infection. Nat Rev Gastroenterol Hepatol 2011;8:257-64.

32. Dore GJ, ed. Clinical interventions toward the eradication of HCV. 2nd Canadian Symposium on Hepatitis C Virus. Victoria, March 4, 2013.

33. Grebely J, Tyndall MW. Management of HCV and HIV infections among people who inject drugs. Curr Opinion HIV AIDS 2011;6:501-7.

34. Rhodes T, ed. Mapping the Social aspects of hepatitis $\mathrm{C}$ among people who inject Drugs. 2nd Canadian Symposium on Hepatitis C Virus. Victoria, March 4, 2013.

35. Rhodes T, Harris M, Martin A. Negotiating access to medical treatment and the making of patient citizenship: The case of hepatitis C treatment. Sociol Health Illness 2013;35:1023-44.

36. Harris M, Rhodes T. Hepatitis C treatment access and uptake for people who inject drugs: A review mapping the role of social factors. Harm Reduct J 2013;10:7.
37. Sockalingam S, Dodd Z, Meaney C, Mason K, McKay R, eds. "It's Good That The Group is Here" - An evaluation of a psycho-social group to support engagement with HCV treatment.

2nd Canadian Symposium on Hepatitis C Virus.

Victoria, March 4, 2013

38. Smith B, ed. Population-based strategies for HCV testing. 2nd Canadian Symposium on Hepatitis C Virus. Victoria, March 4, 2013

39. Smith BD, Morgan RL, Beckett GA, et al. Recommendations for the identification of chronic hepatitis $\mathrm{C}$ virus infection among persons born during 1945-1965. MMWR Morb Mortal Wkly Rep 2012;61(RR-4):1-32.

40. Ly KN, Xing J, Klevens RM, Jiles RB, Ward JW, Holmberg SD. The increasing burden of mortality from viral hepatitis in the United States between 1999 and 2007. Ann Intern Med 2012;156:271-8.

41. Trubnikov M, Njihia J, Yan P, Archibald C, eds. Increased reported rates of HCV in Canadian "baby boomers": Results of a 20 year cohort analysis of nationally reported data. 2nd Canadian Symposium on Hepatitis C Virus. Victoria, March 4, 2013.

42. Wong $T$, ed. Hepatitis $C$ birth cohort screening. 2nd Canadian Symposium on Hepatitis C Virus. Victoria, March 4, 2013.

43. Sebastiani G, Ghali P, Wong P, Klein M, Deschenes M, Myers RP, eds. Physician practices for liver fibrosis assessment in chronic hepatitis C: A nationwide Canadian survey. 2nd Canadian Symposium on Hepatitis C Virus. Victoria, March 4, 2013.

44. Krahn M, ed. Modeling in Hepatitis C. 2nd Canadian Symposium on Hepatitis C Virus. Victoria, March 4, 2013

45. Martin NK, Vickerman P, Grebely J, et al. HCV treatment for prevention among people who inject drugs: Modeling treatment scale-up in the age of direct-acting antivirals. Hepatology Mar 28, 2013. doi: 10.1002/hep.26431 (Epub ahead of print).

46. Australia Co. Third National Hepatitis C Strategy 2010-2013. Commonwealth of Australia, 2010.

47. Government TS. Hepatitis C Action Plan for Scotland Phase II: May 2008 - March 2011. The Scottish Government.

48. Services USDoHH. Combating the Slient Epidemic of Viral Hepatitis - Action Plan for the Prevention, Care \& Treatment of Viral Hepatitis. U.S. Department of Health \& Human Services 


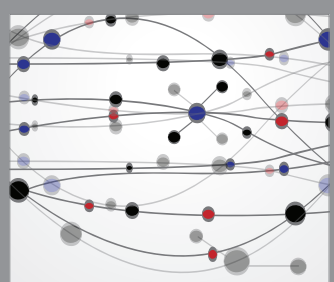

The Scientific World Journal
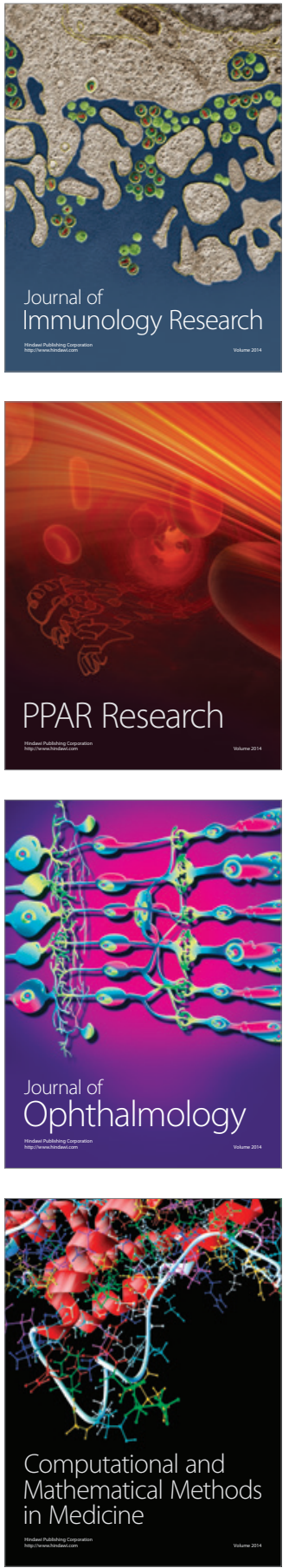

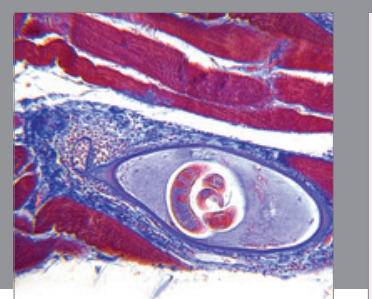

Gastroenterology Research and Practice

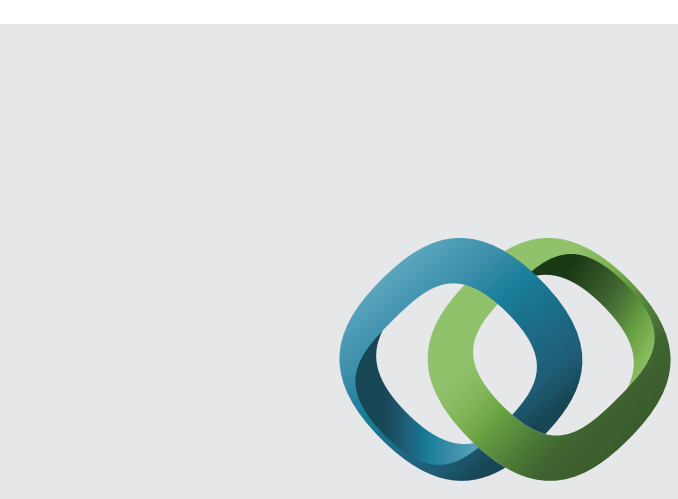

\section{Hindawi}

Submit your manuscripts at

http://www.hindawi.com
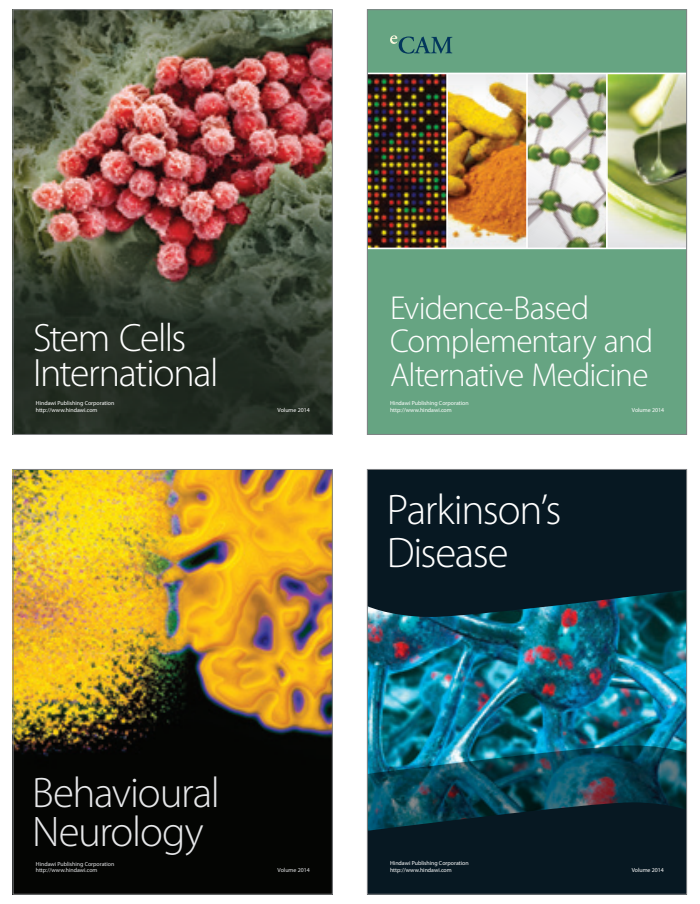
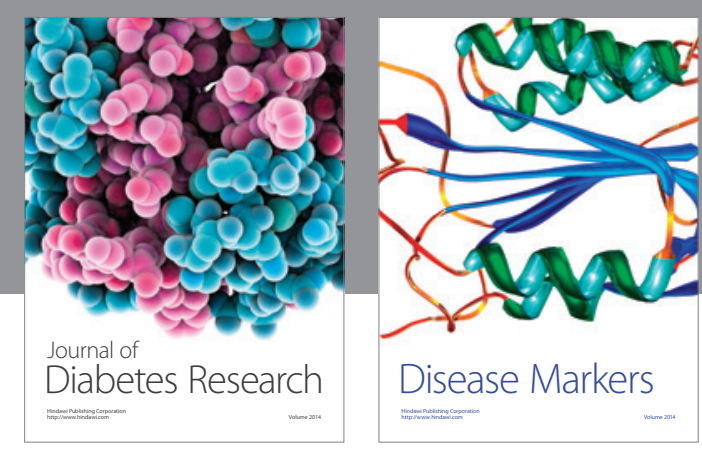

Disease Markers
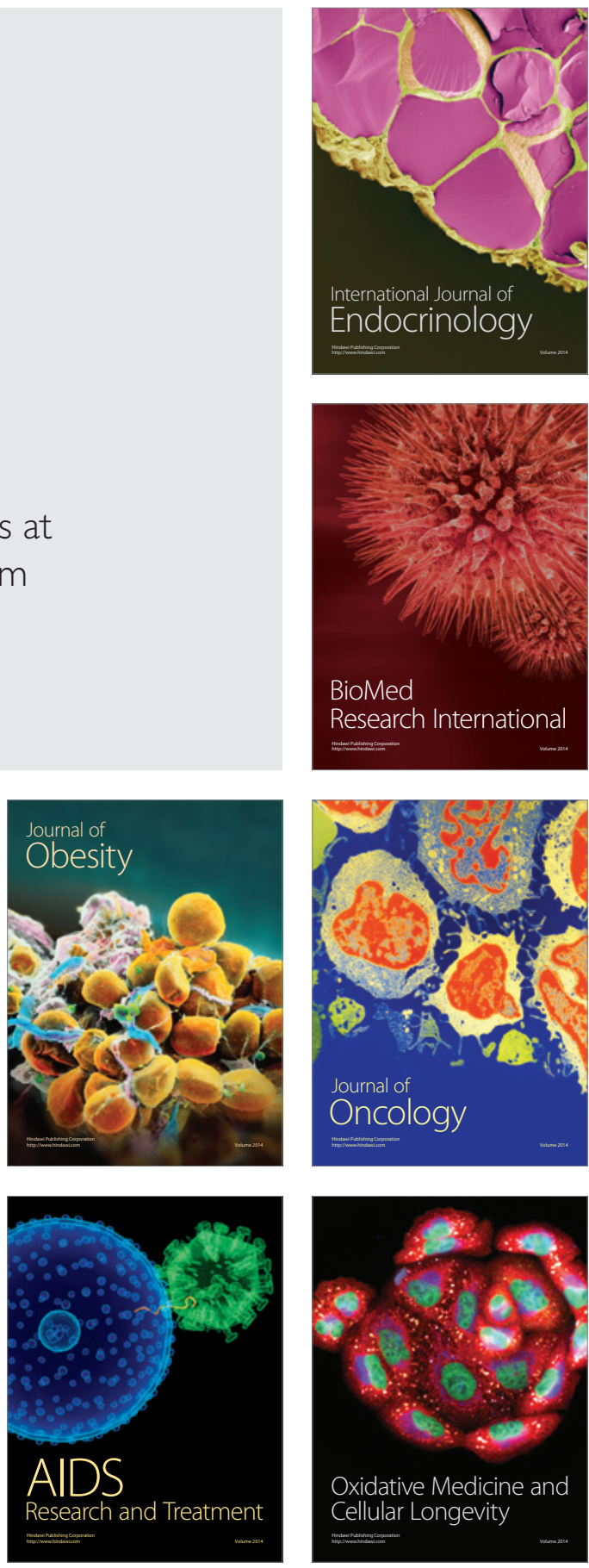